\title{
Um olhar sobre o patrimônio industrial da cidade: memórias dos ferramenteiros de Joinville-SC
}

\author{
Una mirada al patrimonio industrial de la ciudad: recuerdos de fabricantes \\ de herramientas de Joinville-SC \\ A look at the city's industrial heritage: memories of toolmakers from \\ Joinville-SC
}

\author{
Dra. Christina Heloisa Kalb ${ }^{1}$ \\ Dra. Mariluci Neis Carelli ${ }^{2}$
}

\begin{abstract}
Resumo
O objetivo deste artigo é analisar o processo de formação do patrimônio industrial a partir das memórias dos ferramenteiros que iniciaram as primeiras ferramentarias para moldes plásticos em Joinville. Nesta região catarinense existem fábricas que no início do século XIX se estabeleceram na cidade. O patrimônio industrial existente está incorporado de várias formas, principalmente, composto do setor metalmecânico, plástico e indústria têxtil. Estas indústrias são a figura substancial na formação sócio-cultural-econômica da cidade, como um centro de indústria na região. A primeira ferramentaria, propriamente dita, surgiu durante a década de 1980, por causa da proibição, pelo governo brasileiro, da importação de máquinas estrangeiras. Esta decisão do Estado refletiu dentro de grandes empresas, excluindo do processo de produção as ferramentarias. Os profissionais demitidos destas empresas, foram encorajados a abrir seus próprios negócios, ocorrendo então, a terceirização desses serviços de ferramentarias. A metodologia aplicada nesta pesquisa foi a história oral, através de realização de entrevistas semiestruturadas e houve pesquisa documental e bibliográfica.
\end{abstract}

Palavras-Chave: Ferramentarias; Indústrias; História Oral; Memórias; Patrimônio Industrial.

\section{Resumen}

El objetivo de este artículo es analizar el proceso de formación del patrimonio industrial a partir de los recuerdos de los fabricantes de herramientas que comenzaron las primeras herramientas para moldes de plástico en Joinville. En esta región de Santa Catarina hay fábricas que a principios del siglo XIX se establecieron en la ciudad. El patrimonio industrial existente se incorpora de varias maneras, principalmente compuesto por la industria metalmecánica, plástica y textil. Estas industrias son la figura sustancial en la formación sociocultural-económica de la ciudad, como centro de la industria en la región. El primer taller de herramientas apareció en la década de 1980, debido a la prohibición del gobierno brasileño de importar maquinaria extranjera. Esta decisión del Estado se reflejó en las grandes empresas, excluyendo los talleres de herramientas del proceso de producción. Se alentó a los profesionales despedidos de estas empresas a abrir sus propios negocios, luego, se produjo la subcontratación de estos servicios de herramientas. La metodología aplicada en esta investigación fue la historia oral, a través de entrevistas semiestructuradas y hubo investigación documental y bibliográfica.

Palabras clave: herramientas; Industrias; Historia oral; Recuerdos; Patrimonio industrial.

\footnotetext{
Abstract

The purpose of this study is to understand the process of formation of the industrial heritage from the memories of the toolmakers who started the first tooling for plastic molds in Joinville. In this region of Santa Catarina there are

1 Doutora em Ciências Humanas; Complexo de Ensino Superior de Santa Catarina -CESUSC; Florianópolis, Santa Catarina, Brasil; christianekalb@ hotmail.com

2 Doutorado em Engenharia de Produção; Universidade da Região de Joinville - Univille; Joinville, Santa Catarina, Brasil; mariluci.carelli@gmail.com
} 
factories that established themselves in the city in the early nineteenth century. The existing industrial heritage is incorporated in several forms, mainly composed of the metal-mechanical sector, plastic and textile industry. These industries are the substantial figure in the city's socio-cultural-economic formation, as an industry center in the region. The first tooling, properly speaking, arose during the 1980s, because of the prohibition by the Brazilian government of the importation of foreign machines. This decision of the State reflected within large companies, excluding from the production process the tool shops. The professionals dismissed from these companies were encouraged to open their own businesses, and then outsourcing these tooling services. The methodology applied in this research was oral history, through semi-structured interviews and documental and bibliographic research.

Keywords: Toolmakers; Industries; Oral History; Memories; Industrial Heritage.

\section{Introdução}

O entendimento de que determinadas áreas industriais possuem valor histórico, artístico/estético e, principalmente, cultural para determinada sociedade e por óbvio, para o mundo hoje globalizado, pressupõe análises mais apuradas da integralidade destas áreas, enquanto símbolo de uma localidade, bem como a sua interação social, seu entorno, suas memórias, que neste instante torna-se cogente de maiores explicações. Portanto, temos como objetivo compreender o processo de formação do patrimônio industrial a partir das memórias dos ferramenteiros que iniciaram as primeiras ferramentarias para moldes plásticos na cidade de Joinville - SC.

Este processo de alargamento de entendimento do que se faz cogente proteger e consequentemente, quando necessário, restaurar, Choay (2001, p.11) afirma que o patrimônio cultural, especificamente o industrial passou a considerar não apenas as grandes obras isoladas de qualidade excepcional, mas centros urbanos ou rurais inteiros dando-se maior importância ao tecido urbano e à "arquitetura vernacular", passando a abranger também construções recentes, como aquelas incluídas ao patrimônio industrial. Assim:

A cultura do trabalho, os padrões éticos de sobrevivência, a consciência dos quadros de produção e da sua inserção no mercado, a apreensão dos modelos tecnológicos dominantes, as formas de mobilização das pessoas e dos espaços, eis alguns pólos para esse diálogo, que se podem traduzir tanto em intervenções letivas breves e monodisciplinares, como em projetos de escola mais abrangentes de natureza inter e transdisciplinar (ALVES, 2004, p. 252).

A memória do patrimônio industrial, por sua vez é considerada um bem intangível, na qual abarca tudo que se refere ao saber fabricar, desde a constituição da fábrica até o seu produto final, ou seja, considera o engenho humano uma habilidade a ser preservada na memória coletiva, mesmo que de forma apenas a ser registrada e não mantida, em razão da notória tecnologia hoje desenvolvida e aplicada às indústrias e invenções, contudo, não há muitas referências científicas que tratam do assunto, além do que, por ora nosso intento não é aprofundar os debates sobre o saber fazer do ofício e/ou profissional ferramenteiro e sim, 
analisar o patrimônio industrial de modo mais amplo, apesar de compreendermos a importância dessa perspectiva cientifica.

Aos poucos, o conceito e entendimento de patrimônio industrial e de certa forma, o reconhecimento da arqueologia industrial como disciplina a ser estudada vem sendo incorporadas às noções de valorização dentro do conceito amplo e genérico de patrimônio histórico-cultural e, assim, "estes passaram a ser considerados um bem cultural que devia ter reconhecimento jurídico, uma estrutura administrativa e uma política nacional e regional de proteção" (SOLER, 1992, p. 15 apud CAMPAGNOL, 2008, p. 414).

O valor histórico-cultural dos estudos destes sítios (locais de fábricas ou indústrias) é representado pela sua importância na esfera mundial, em razão de suas consequências históricas e sociais nos registros do cotidiano de muitos operários e operárias, bem como dos empresários que detinham um mesmo sentimento, além é claro de ser parte integrante da identidade do povo e da herança cultural. Assim, "as investigações históricas e sociológicas no campo possuem, porém, longa genealogia, através de estudos de diversos autores sobre história das ciências, da técnica, econômica e social, voltados aos processos de industrialização, produção de energia e meios de transporte" (KUHL, 2006, p.1).

Vale lembrar ainda que "a restauração de bens culturais, [...] é um campo disciplinar que começa a adquirir autonomia há pelo menos um século, com dois séculos de experiências práticas e formulações teóricas sistemáticas já acumuladas" desta forma "não se trata de conservar tudo, nem, tampouco, de demolir ou transformar radicalmente tudo, [...] é necessário fazer escolhas conscientes, baseadas em conhecimento aprofundado, para que os bens mais significativos possam ser preservados e valorizados" (KUHL, 2006, p.3), assim Sousa (2010, p.143) coaduna com o entendimento de Kühl quando discorre que:

\begin{abstract}
é necessário reconhecer que exemplares de todas as épocas e as várias fases de produção humana são merecedores de estudos. Isso não quer dizer que devemos preservar todo e qualquer testemunho do passado, por isso a importância desses estudos e análises, para que se possa reconhecer e selecionar os exemplares dignos de serem preservados por seus valores históricos, estéticos, afetivos ou memoriais (KUHL, 2006, p.3).
\end{abstract}

Ulpiano de Meneses analisa a produção da arqueologia industrial e menciona que um estudo sobre a indústria que "não pode limitar-se, nunca, às manufaturas e aos equipamentos e às instalações destinadas a sua fabricação, mas deve incluir todos os sistemas de trabalho que podem ser funcionais para a reprodução da indústria e seus capitais” (MENESES, 1983, p.226).

Observado esses primeiros passos na direção de uma preservação mais consciente do patrimônio industrial, agora, faremos um breve levantamento histórico de certos eventos 
pontuais da cidade de Joinville, entrelaçado a fatos ocorridos em nosso país, que de alguma forma influenciaram na formação da malha urbana.

\section{Ressoar de fatos históricos no Brasil e Joinville}

As guerras e a crise de 1929 nos EUA modificaram sensivelmente o setor industrial, em razão da "necessidade de substituir as importações para atender à crescente demanda interna por bens de consumo final” (FIESC, 2000, p.36). A Revolução de 1930 colocou no poder "o latifúndio ligado ao mercado interno, a indústria brasileira e os bancos americanos" (MAMIGONIAN, 1988, p.37 apud ROCHA, 1997, p.47).

Vale lembrar que a partir da colonização da cidade (iniciada em 1851) de Joinville, e sua expansão, haviam poucas empresas constituídas, sendo uma delas, a empresa de confecção de tecidos, Döhler S/A. Nas décadas de 1930 e 1940 várias empresas surgiram na região da cidade de Joinville, como foi o caso da Meister Metalgráfica e Fundição Tupy, bem como White Martins, Buschele \& Lepper e Consul. Aos poucos "a concentração industrial transformaria Joinville na maior cidade do Estado, pois a necessidade de mão de obra promoveu um fluxo migratório significativo de trabalhadores que se deslocaram de outras cidades catarinenses e de estados vizinhos" (FICKER, 2008, p.96). A companhia Tupy, por exemplo, "produzia muitos componentes metálicos antes de sua mudança tecnológica para o uso de material termoplástico com a marca 'Tigre' [de forma que] a companhia criou residências destinadas a parte de seus empregados" (CORREIA, GUNN, [20??], p.32).

A partir de 1938 (FIESC, 2000, p. 40), o então Presidente Getúlio Vargas, iniciou uma campanha chamada nacionalista, que teve como consequência a perseguição aos alemães e italianos em todo o sul do país (incluindo Joinville) por suspeitas destas pessoas estarem envolvidas com o nazi-fascismo. Desta forma, "com a entrada do Brasil na 2a Guerra, Vargas nomeou Nereu Ramos como interventor em Santa Catarina, dando início a uma verdadeira caça às bruxas contra os imigrantes de origem alemã e italiana” (FIESC, 2000, p. 40). Há vários relatos, inclusive dos entrevistados nessa pesquisa, que mencionam eventos envolvendo seus familiares, decorrentes da campanha de nacionalização, onde casas e empresas eram marcadas com o símbolo da suástica, pois se desconfiava de haver algum envolvimento com o nazifascismo, muitas vezes, pelo simples motivo de se falar alemão.

No final da Segunda Guerra, Joinville e as outras cidades próximas entraram numa nova fase da industrialização, com bases sólidas e diversificadas através das novas empresas estabelecidas na região, prontas para enfrentar o mercado externo. "A guerra desencadeou o crescimento das indústrias pela substituição forçada de importações e pelas oportunidades de 
vendas ao mercado externo, principalmente à América Latina” (ROCHA, 1997, p.54). De modo que, de acordo com Ternes (1993, p.158), com o "boom econômico, fortemente ajudado pelo espírito familiar e a conhecida disciplina alemã, explicam a nova geografia e o novo urbanismo da cidade, a partir da década de 50".

No período do pós-guerra (TERNES, 1993, p.60), finalmente o governo brasileiro liberou as importações das máquinas, porém proibiu a associação de empresas brasileiras com estrangeiras, criando problemas sérios de transferência de tecnologia de fora para dentro. Assim, "ocorria intensa substituição de importações, principalmente nas indústrias de bens intermediários e nas indústrias de bens de consumo durável [...]" (ROCHA, 1997, p.54), como forma de burlar a proibição estatal, vez que os empresários brasileiros aprendiam com a vinda das máquinas importadas com estas novas tecnologias, sem precisar se associar com as fabricantes estrangeiras.

As escolas/universidades da região vieram suprir a falta de qualificação dos trabalhadores da cidade, bem como os que vinham para a cidade se especializar e depois de formados, buscavam melhores colocações nas cidades vizinhas ou nos grandes centros. A qualificação escolar que aqui se exigia nunca foi exigida dos artesãos, do trabalhador rural, quiçá do escravo, por isso a grande importância da educação na cidade e no país como um todo. Era uma necessidade precípua para o crescimento nacional.

Já nos anos 1980, conforme bem explica Rocha (1997, p.59), as indústrias de Joinville já bastante amadurecidas investiram fortemente na fundação de novas unidades fabris, em outros Estados brasileiros, de suporte para a principal atividade ou mesmo em outros setores, formando grupos empresarias e as holding's, como foi o exemplo das empresas Tupy, Multibrás (Whirlpool S/A), dentre outras.

Porém neste mesmo período "a cidade registrou a maior população em relação às demais cidades de Santa Catarina" gerando assim, "uma série de problemas de infraestrutura" obrigando o poder estatal a tomar medidas para "inibir a migração" (COELHO, 2011, p.59). Ternes complementa que nas décadas de 1970 e 1980, ainda, a cidade de Joinville "sofre de uma singular perda de identidade, desfigurando-se de suas características históricas. Trata-se, então, do ápice de um processo de desintegração cultural que se iniciara há 30 anos, a partir da acelerada industrialização e da urbanização descontrolada" (TERNES, 1993, p.188). Além disso, conforme conclusão de Ilanil Coelho (2011, p.30) em sua obra "Pelas tramas de uma cidade migrante", a cidade "passa a revelar de maneira mais intensa os desdobramentos das suas transformações econômicas, sociais e culturais", de modo que a indústria começa a se reestruturar, em razão do "emprego industrial" e das novas tecnologias voltadas para a 
urbanidade - serviços sociais, bem como para os processos industriais. A cidade começa a perder o aspecto estritamente germânico que tinha até então e inicia um processo de cosmopolitismo, o que gerou críticas como a de Ternes acima mencionada.

A partir da década de 1990, "esse domínio da falta de quase tudo foi quebrado [...] quando as empresas, tendo de reduzir custos, terceirizando serviços, notadamente os de mão de obra intensiva. Novas e pequenas empresas foram criadas, as recreativas passaram também a ser administradas por terceiros" (COELHO, 2011, p.61). Existem em atividade, ainda hoje, algumas das fábricas que a partir do início do século $\mathrm{XX}$ se instalaram em Joinville, que constituíram o centro da cidade, na qual circundam o rio Cachoeira, rio que corta toda a cidade e que era o meio de transporte das mercadorias ali feitas / beneficiadas para o porto mais próximo, na cidade de São Francisco do Sul/SC.

Realmente, durante o período de colonização até meados do século XX, muitos trabalhadores deslocaram-se do interior do Estado de Santa Catarina e do Paraná para a cidade de Joinville a procura de melhores salários e, consequentemente, uma melhor condição de vida. De todo modo, com o passar das décadas e com a evolução da indústria e tecnologia, Joinville tornou-se uma cidade predominantemente industrial e, por conseguinte, possui um patrimônio industrial considerável a realização de estudos, além de ser conhecida nacionalmente e até mesmo internacionalmente, atualmente pelo seu grande porte industrial, considerada o $2^{\circ}$ pólo brasileiro de fundição (O PRIMEIRO..., 2011, p.1).

As grandes empresas que nesta cidade iniciaram seus processos de produção aos poucos foram se especializando, principalmente a partir da década de 1990, e deixando de criar máquinas juntamente com seus produtos comercializáveis, já que o processo produtivo foi se subdividindo dentro de outras empresas, como é o caso das ferramentarias, fundições, que aos poucos, através do processo de downsize foi se deslocando das grandes empresas para as empresas especializadas em moldes e matrizes.

Ilanil Coelho (2011, p.70) explica esta situação, pois "nos anos 90, as empresas joinvilenses, de internacionalizadas, passaram a se tornar cada vez mais globalizadas, pois além de buscarem novas oportunidades de negócios em escala global também descentralizaram a produção", aproveitando a alta tecnologia e mão de obra disponível no local, de modo que à medida que as indústrias locais se globalizaram, caiu o potencial de geração de novos empregos industriais e ondas demissionárias tornaram-se frequentes. Foi o que ocorreu com grande parte das empresas retromencionadas, bem como outras diversas de significativa importância para a cidade. 
A partir de agora traremos as memórias propriamente ditas dos primeiros ferramenteiros, na época dos anos oitenta, recém-empresários. Esses entrevistados que em sua maioria tinham sido demitidos, em razão da onda de terceirização dos serviços dentro das grandes fábricas, foram, portanto, 'obrigados' a se reinventar, através de pequenas empresas dentro do ramo da ferramentaria.

\section{Das Memórias dos ferramenteiros....}

O processo de colonização germânico na cidade de Joinville foi uma das grandes causas da formação do aglomerado eletro-metal-mecânico, composto por inúmeras pequenas atividades mercantis e manufatureiras, bem como de polímeros, vez que ambas se entrelaçam durante os processos de produção industriais.

Estudar, pois o Imaginário Social de uma determinada sociedade é “dialogar com seu mistério, com suas crenças mais profundas" (COELHO, 2011, p.67), vez que é o local onde se "escondem" as representações sociais daquele povo. Afinal, Candau (2011, p.19) menciona que não há uma procura de identidade sem memória e da mesma forma, uma busca pela memória sempre vem anexa a um sentimento de identidade, ao menos de cada indivíduo. Entendimento este totalmente relacionado com as memórias advindas dos ferramenteiros de Joinville. Portanto, a partir deste momento apresenta-se a seleção dos depoimentos dos profissionais que atuam ou atuaram na área das ferramentarias em Joinville, depoimentos que são intercalados por suas respectivas análises, vez que representam a memória dos ferramenteiros da cidade. Optamos por não nomear os depoimentos.

Deve-se ressaltar inicialmente que a "especialização metal-mecânica da indústria local foi fortemente influenciada pelo pioneirismo de Otto Bennack, cuja oficina voltada à produção de tornos, foi fundada em 1893" (BAKKAR, 2009, p.37), na cidade de Joinville. A oficina mecânica de Bennack foi, certamente, modelo para outras diversas que iniciaram seus próprios negócios com capital não-ervateiro, vez que era o negócio mais vantajoso na época, “apesar de Joinville situar-se distante do centro econômico nacional, a diversificação e ampliação da estrutura produtiva local indicam certo dinamismo, sobretudo, dos segmentos da eletrometalmecânica, em acompanhar o processo de industrialização brasileira” (BAKKAR, 2009, p.37).

Portanto, de acordo com as memórias inseridas no vídeo intitulado: Registro do desenvolvimento das ferramentarias de Joinville (SACCHELI, 2009). Os primeiros funcionários e também os próprios fundadores destas ferramentarias eram profissionais muito criativos e ajudaram na implantação e desenvolvimento das empresas. A criatividade destes 
técnicos especialistas na fabricação de moldes surgiu da necessidade em inovar, transformando literalmente ideias em projetos de papel. Ato este bastante preciso, delicado, do ponto de vista do engenho da criação, bem como original, vez que cada molde corresponde a uma peça que será produzida futuramente, molde este vindo do intelecto humano. E ainda, interessante lembrar que a fabricação de ferramentas para a injeção de plásticos tem um grau de complexidade e precisão considerável, vez que requer grande experiência e capacidade dos profissionais, para se ter uma ideia, o tempo de confecção de uma ferramenta podia chegar a meses, de modo que o produto tinha (e continua tendo) um valor agregado muito alto.

Grande parte dos produtos são/eram criados sob encomenda, e normalmente são inéditos, o que implica também num elevado grau, ainda hoje, de desenvolvimento tecnológico referente às máquinas e equipamentos, para as empresas terem condições de competir no mercado externo.

Os moldes para as empresas de fundição, por exemplo, são os principais produtos das empresas joinvilenses, assim as grandes fundições alocam uma elevada escala de produção, ultrapassando os limites de demanda, de maneira que essas empresas necessitam recorrer a outras firmas locais, através da terceirização, sem que isso comprometa, a princípio, a qualidade dos produtos que exigem alta precisão. Assim, veio se destacando as iniciativas para o desenvolvimento tecnológico e as cooperações empresariais, através da aliança entre as empresas posicionadas nos distintos estágios de produção, por meio dos condomínios industriais.

O surgimento dessas ferramentarias, além de outras tantas empresas da região, decorreu da proibição da importação de máquinas vindas do estrangeiro, obrigando diversas grandes empresas a demitir seus trabalhadores, todavia os estimulando a abrir seus próprios negócios, terceirizando os serviços de ferramentarias que anteriormente era desenvolvido dentro da própria empresa. Exemplo disso ocorreu nas empresas Embraco e Consul (hoje denominadas Whirlpool S/A), Cipla, Tupy e Tigre, empresas de grande porte e reconhecidas nacionalmente.

Um dos entrevistados relata que a cidade de Joinville sempre foi considerada por possuir um pólo industrial muito forte, coadunando com o que foi dito. E que em sua maioria, os ferramenteiros não eram moradores da cidade, porém sabendo da grande produtividade e empregos que aqui se dispunham, resolveram mudar-se para a maior cidade do Estado de Santa Catarina (em população), em busca de melhores condições de vida e, consequentemente, uma melhor posição profissional.

O setor metal-mecânico é parte integrante das ferramentarias. Assim, os depoimentos a seguir transcritos revelam que o processo de downsize, dentro das grandes empresas foi o 
grande causador do surgimento da maior parte das novas ferramentarias até então inexistentes. Processo que, conforme o depoente relembra fez com que

a Embraco eliminasse pessoal, a Hansen Máquinas fechou cem por cento, eram trezentos a quatrocentos funcionários, ela acabou fechando de uma hora para a outra. A Cipla acabou diminuindo a ferramentaria, também a Embraco acabou diminuindo, bem como a Multibrás. Enfim, [...] a Tupy acabou com a ferramentaria. Ou seja, essa explosão (processo de downsize) de fechar com as ferramentarias, acabou sobrando muita mão de obra, e não tinha tantas empresas, nem tantos empregos (depoimento) (SACCHELI, 2009).

O depoente acima demonstra através de suas memórias que ao mesmo tempo que o processo de downsize foi decisivo para o início das "novas" ferramentarias, foi um grande gerador de desemprego para a região. A partir deste novo boom industrial na cidade de Joinville, que surgiram estas diversas empresas de ferramentarias, ainda que pequenas. Este é o grande motivo de hoje a cidade ter um grande destaque no setor, sendo referência nacional no pólo de fundição. Ainda outro depoente, neste mesmo sentido afirma que "muita gente que se aposentou junto a Tigre, chegou a comprar torno, financiado e trabalhava, não mais para a Tigre, mas para outras empresas (depoimento)" (SACCHELI, 2009).

Realmente, a união destes profissionais das ferramentarias (amigos e/ou parentes), fez as primeiras empresas se formarem gradativamente, porém nesta época (década de 1990), o governo não permitia importação de máquinas estrangeiras, assim, os novos empreendedores, compravam a licença dos fabricantes europeus, que traziam as plantas das máquinas e de acordo com outro entrevistado "aqui era então feito, totalmente nacional [...], mais tarde inclusive havia o setor de fundição de peças metálicas da Tigre, onde era fundido, e torneado conexões de ferro fundido para tubos de PVC" (depoimento) (SACCHELI, 2009).

Além das empresas, por meio desta união, surgiu também o Núcleo de Usinagem e Ferramentaria da ACIJ - Associação Empresarial de Joinville, núcleo mais antigo da associação, que obteve este modelo estrutural do sistema da Baviera, na Alemanha. O Núcleo iniciou, de acordo com depoimento de um ferramenteiro "em 1992, com a ideia do Prof. Max, e sua própria colaboração, porque havia um sistema da Câmara da Auto Baviera, da Alemanha, que possuía uma parceria de treinamentos, assegurando a formação do profissional ferramenteiro" (depoimento) (SACCHELI, 2009).

Percebe-se que realmente a profissão de ferramenteiro sempre possuiu certas virtudes peculiares, como a criatividade, inovação e organização. A criatividade vê-se pela capacidade de invenção e imaginação de moldes, produtos, enfim, meios de se criar algo a partir da arte dos desenhos. A inovação está completamente unida à criatividade, porém esta capacidade é 
complementar a ela, vez que inovando, têm-se as constantes transformações tanto de produtos finais, como também a forma de produção destes produtos. E ainda a organização, como bem citado anteriormente, os ferramenteiros são muito organizados, a tal ponto de criar um núcleo setorial, dentro da Associação Empresarial da cidade, que trate das dificuldades e conquistas de um setor extremamente concorrente.

O aprimoramento técnico das empresas inicialmente era feito pela busca de mão de obra especializada no exterior, muitas das vezes, na Alemanha, país que trouxe vários colonizadores para Joinville, em meados do século XIX. Contudo, não só europeus qualificados eram trazidos para a cidade, mas também os proprietários das indústrias e seus filhos (as) eram para lá enviados, para aprender o modo de fabricar, inventar, inovar nos cursos e estágios nas empresas europeias, principalmente alemãs.

Outro ferramenteiro ainda relembra que

algumas ferramentarias não fabricavam moldes, mas peças técnicas, que serviam para a fabricação de outras máquinas e que grande parte das ferramentarias que iniciaram as suas atividades na cidade, realmente começou com a união de dois ou mais amigos ferramenteiros (depoimento) (SACCHELI, 2009).

Todas estas memórias dos ferramenteiros de Joinville nos fazem acreditar que apesar da crise econômica que ocorreu durante as décadas de 1980 e 1990, as empresas desses setores / destes empresários e ex-funcionários, conseguiram se manter em funcionamento, seguindo algumas regras estruturais. De modo que "não pode haver construção de uma memória coletiva se as memórias individuais não se abrem umas às outras visando objetivos comuns, tendo um mesmo horizonte de ação" (CAUDAU, 2011, p.48).

Bakkar (2009, p.48) indica, então, quais seriam estas estratégias, mas destaca a reestruturação patrimonial e produtiva, a desverticalização da produção, direcionando seus esforços à especialização em linhas de produtos que são mais competitivas. E nessa conjuntura econômica, marcada pelo acirrado cenário internacional de concorrência, as empresas da região, buscaram reduzir seus custos realizando as primeiras demissões em massa de seus funcionários em consequência da automatização e terceirização das etapas de seus processos produtivos. Esse amplo processo de reestruturação, realizado pelos grandes grupos empresariais deu origem ao surgimento de inúmeras micro e pequenas empresas, que viram na região um importante espaço de atuação, principalmente através da prestação de serviços industriais complementares, como ocorreu com as ferramentarias. 
Joinville é uma cidade-destaque no setor, cujas atividades são amplamente diversificadas, como se observa com as condições citadas por Bakkar (2009, p.37), a seguir, empresas essenciais na vida cultural e econômica da cidade:

- fundições de grande porte, produzindo blocos de motores e peças automotivas, eletrotécnicas para o mundo todo, tanto em ferro como alumínio (Ex: Tupy e Wetzel);

- fábrica de compressores para equipamentos eletroeletrônicos (Ex: Embraco);

- fábrica de geladeiras, freezer e ar-condicionado (Ex: Multibrás);

- fábrica de compressores de ar para aplicações diversas (Ex: Schulz);

- fábrica de metais sanitários (Ex: Docol);

- fábrica de carrocerias para ônibus (Ex: Busscar);

- fábrica de porcas, parafusos e demais elementos fixadores;

- fábrica de motobombas e equipamentos de médio e pequeno porte;

- outras fábricas no setor de máquinas e produtos metalúrgicos: além dos setores acima referidos, outras indústrias têm sido instaladas no município, tais como plástico (Ex: Tigre, Amanco e Krona), têxtil (Ex: Döhler e Lepper), químico, farmacêutico e de alimentos.

Algumas destas empresas foram detentoras precipuamente de todo o processo de produção de seus produtos dentro de suas fábricas, que aos poucos foram se desverticalizando e retirando departamentos internos, gerando, assim, as empresas especializadas em determinado setor, como ocorreu com as ferramentarias focadas na fabricação de moldes e matrizes.

Outro entrevistado assegura que

Joinville hoje é o maior pólo de ferramentarias do Brasil, pois considera que o setor de ferramentaria é vital para a economia da cidade, primeiro por ser um segmento que produz ferramentas para os produtos que serão lançados. Então as inovações de produtos que estão no mercado passam de uma forma ou de outra pelas ferramentarias da cidade, seja no lançamento de um veículo novo, de um eletrodoméstico ou algum produto na área de construção civil, pois basicamente toda a estrutura necessária para o lançamento de um produto passa por ferramentarias de Joinville (depoimento) (SACCHELI, 2009).

Contudo, vale esclarecer que a indústria ferramenteira de moldes e matrizes para injeção de plásticos faz parte de uma família industrial, que se subdividem em quatro especialidades, quais sejam: a indústria de corte, dobra e repuxo; a indústria de dispositivos (usinagem, controle e soldagem) e; a de modelação de metais (para fundição) por meio da metalurgia, somando os termoplásticos às 3 áreas de atividade.

Apesar de estar vinculado a um mercado bastante diversificado, tanto regional, como nacional, esse pólo industrial tornou-se bastante conhecido pela sua excelência no atendimento 
aos moldes da construção civil, linha branca e autopeças, possuindo a chancela de ser considerado o $2^{\circ}$ maior pólo industrial brasileiro, no que concernem às fundições.

Percebe-se com isso que o patrimônio industrial voltado às ferramentarias na cidade já se tornou há muito a identidade cultural deste lugar. Vez que o que constitui patrimônio para Claudia Carvalho (2008, p.36) envolve, em primeiro lugar, um conjunto de posses que cumpre identificar como transmissíveis, como ocorre na questão da cultura industrial da cidade, uma vez que ainda há muitos jovens que têm como sonho de trabalho, seguir seus pais, na qual sempre trabalharam na seara fabril, fundindo e torneando peças, criando moldes e matrizes. Em seguida, um grupo humano, uma sociedade, capaz ou suscetível de reconhecê-las como suas, de demonstrar a sua coerência e de organizar a sua recepção, como também ocorreu em Joinville, cidade que exporta grande parte de seus produtos produzidos para o comércio exterior, considerada assim um pólo industrial de fundição, reconhecida por este patrimônio industrial.

Para se constituir um patrimônio na cidade é necessário que possua um conjunto de valores, políticos no sentido mais geral do termo, que permite articular os legados do passado à espera ou à configuração de um futuro, como o objetivo de promover algumas mutações e, ao mesmo tempo, afirmar uma continuidade. Fato que ocorre todos os dias na cidade, contudo não só nos bairros onde estão as fábricas, mas isso se sente no centro, onde a pulsação industrial borbulha, ferve de sentimentos pelo trabalho e por buscar uma vida melhor e mais confortável para a família e para o indivíduo em si.

A cultura industrial de Joinville, ou seja, este patrimônio imaterial é algo que não mudará tão cedo, pois este olhar de cidade trabalhadora e preocupada com seu futuro passa de geração para geração dentro de muitas famílias. A perda desta "memória é, portanto, uma perda de identidade" (CARVALHO, et al., 2008, p.36) da cidade. Mas, obviamente que não podemos generalizar e entender Joinville como sendo uma cidade, "simplesmente", para o trabalho. É também uma cidade para o lazer, para as festas, e tantos outros usos e atribuições, como podemos mencionar por ora, através da Festa das Flores, e o Festival de Dança, patrimônio declarados da cidade.

\section{Considerações Finais}

As observações e análises aqui demonstradas estão longe de encerrar por completo. $\mathrm{O}$ estudo do patrimônio industrial, ainda mais no que se refere ao patrimônio joinvilense possui diversas problemáticas que dificultam um diagnóstico mais preciso e completo para este artigo. O que de certa forma foi aprofundado durante a pesquisa de doutoramento encerrado em 2017. 
Este patrimônio, não só as edificações e os vestígios materiais, mas todas as suas formas de expressão material, são alvos da falta de preservação e conservação por parte das autoridades competentes, às vezes de seus proprietários e da própria sociedade, mais também os vestígios imateriais têm se perdido com o passar do tempo, pela ausência de pesquisas na área e de registros propriamente ditos.

As formulações teóricas que se iniciaram desde a década de 1950 , no que concerne à preservação industrial, na Inglaterra, não se verificam concretamente no campo prático, pelo menos no que se refere ao viés brasileiro, o que dificultava ainda mais os meios de proteção destes bens culturais de origem industrial, que muitas vezes se transformam em "gigantes elefantes brancos" sem uma utilização adequada, ou ainda sendo utilizados sem critérios, e sem a verificação de sua referência histórico-social.

No entanto, apesar do otimismo vislumbrado nas entrevistas e em alguns momentos, nas pesquisas das autoras, ameaças ao patrimônio existem todos os dias, principalmente com o crescimento das cidades e a pressão especulatória imobiliária, de modo que não há mais valores reconhecidos e há constantes investidas deformadoras e desinformadas, que chegam a destruir os bens imóveis de valor cultural-industrial. Isso vem ocorrendo tanto nas obras grandiosas de valor artístico, como por outro lado, em obras de interesse histórico ou de valor histórico.

Devemos nos aprofundar nos debates sobre esta temática, justificando as decisões de suas utilizações e promover cada dia mais questionamentos destas atitudes frente a determinado bem, lembrando sempre das dificuldades e especificidades que o patrimônio industrial detém em relação aos bens culturais de uma forma geral.

\section{Referências bibliográficas}

ALVES, Jorge Fernandes. Patrimônio industrial, educação e investigação: a propósito da rota do patrimônio industrial do Vale do Ave. Revista da Faculdade de Letras/História, Porto/Portugal, v. 5, s. 3, pp. 251-256, 2004.

BAKKAR, Muhamad. A indústria eletrometal-mecânica da região de Joinville: do aglomerado industrial ao arranjo produtivo local. $105 \mathrm{f}$. Dissertação (Mestrado em economia). Curitiba: UFPR - Universidade Federal do Paraná, 2009.

CAMPAGNOL, Gabriela. Usinas de açúcar: habitação e patrimônio industrial, $531 \mathrm{f}$. tese (Doutorado em arquitetura e urbanismo). São Carlos/SP: FAUUSP, 2008.

CANDAU, Joël. Memória e identidade. (trad) Maria Leticia Ferreira. São Paulo: Contexto, 2011. 
CARVALHO, Claudia S. Rodrigues, et al. Um olhar contemporâneo sobre a preservação do patrimônio cultural material. Rio de Janeiro: Museu Histórico Nacional, 2008.

CHOAY, Françoise. Alegoria do patrimônio. São Paulo: Estação liberdade UNESP, 2001.

COELHO, Ilanil. Pelas tramas de uma cidade migrante. Joinville: Editora da Univille, 2011.

CORREIA, Telma de Barros; Gunn, Philip. A industrialização brasileira e a dimensão geográfica dos estabelecimentos industriais. São Paulo: USP, 20??.

FICKER, Carlos. História de Joinville: subsídios para a crônica da colônia Dona Francisca. 2 ed. Joinville: Letra dágua, 2008.

FIESC 50 anos. Uma história voltada para a industrialização catarinense. Florianópolis: Expressão, 2000.

KUHL, Beatriz Mugayar. Algumas questões relativas ao patrimônio industrial e à sua preservação. Revista eletrônica do Iphan. São Paulo, 2006.

MENESES, Ulpiano T. Bezerra de. Arqueologia industrial: avaliação e perspectiva. In Memoriam. São Paulo, 1983. p. 221-230.

O PRIMEIRO portal do setor metal mecânico. Disponível em: <www.cimm.com.br> Acess: jul 2012, 2011.

ROCHA, Isa de Oliveira. Industrialização de Joinville-SC: da gênese às exportações. Florianópolis: [s.n], 1997.

SACCHELLI, Carlos M. Registro do desenvolvimento das ferramentarias de Joinville. (multimídia vídeo) Entrevistas Transcritas. Joinville: ed. Eugênio Siqueira, 2009.

TERNES, Apolinário. Joinville: a construção da cidade. Joinville: Seigraph-Bartira, 1993. 